\title{
ATIVIDADE PESQUEIRA E CONSTRUÇÃO DE EMBARCAÇÕES NA COLÔNIA DE PESCADORES Z-18 DO MUNICÍPIO DE UNIÃO/PI, BRASIL
}

\author{
K. P. P. SANTOS*, R. R. SOARES E R. F. M. BARROS \\ Universidade Federal do Piauí (UFPI) \\ kellypolyana@hotmail.com*
}

Artigo submetido em julho/2015 e aceito em novembro/2015

DOI: $10.15628 /$ holos.2015.3205

\section{RESUMO}

Na comunidade de pescadores Z-18, do município de União/PI, evidencia-se uma importância cultural de sobrevivência através do uso dos recursos naturais locais. Dados etnobiológicos a respeito das artes e estratégias de pesca e técnicas na construção e reparo de canoas foram revelados após a aplicação de entrevistas semiestrururadas, observação direta, registro fotográfico e análise quantitativa dos dados. Homens e mulheres participam diretamente da pesca, utilizando-se de oito artefatos, destacando-se o engancho. Foram apontadas 10 espécies de peixes raras e 15 espécies comuns.
Quanto à distribuição do conhecimento etnozoológico por gênero, não houve diferenças significativas, por faixa etária, apenas os jovens possuem menos conhecimento do que adultos e idosos, estes, não diferem significativamente. Quatro espécies vegetais são utilizadas na fabricação e reparo das canoas. Homens e mulheres participam diretamente da pesca (55\%) e (45\%) respectivamente. Os pescadores possuem um amplo conhecimento em relação à atividade pesqueira, sendo esta transmitida de geração a geração.

PALAVRAS-CHAVE: Etnobotânica; Etnozoologia; Canoas; Pesca Artesanal; Produto Pescado.

\section{FISHING ACTIVITY AND CONSTRUCTION OF CRAFT IN COLONY OF FISHERMEN Z- 18 IN UNIÃO/PI, BRAZIL}

\begin{abstract}
This study shows the cultural importance of survival through the use of natural resources in the Z-18 fishing community, of the municipality of União/PI. Ethnobiological data on fishing tackle, strategies and techniques used to build and repair canoes was uncovered through semi-structured interviews, direct observation, photographic record and quantitative data analysis. Both men and women take part in fishing, using eight different items of fishing tackle, the most
\end{abstract}

prominent of these being the hook. As to the distribution of ethnozoological knowledge by gender there was no significant difference, while by age group, only young people have less knowledge then adults and elderly people, while the later are not significantly different. Four species of plant are used to build and repair canoes. The fishermen show extensive knowledge regarding fishing, which is passed on from generation to generation.

KEYWORDS: Ethnobotany, Ethnozoology, Canoes, Traditional fishing, Fish. Product 


\section{INTRODUÇÃO}

Os povos tradicionais englobam uma gama de etnias e modos de vidas semelhantes, baseados principalmente no uso sustentável dos recursos naturais, e variam desde caiçaras, quilombolas até indígenas, passando pelos pescadores artesanais, sendo, a maioria desses estudos realizados em comunidades que são, até certa dimensão, isoladas em ambientes costeiros ou rurais e tem um modo de vida baseado principalmente na pesca, ainda que exerça outras atividades econômicas complementares, como extrativismo vegetal, a pequena agricultura e o artesanato (DIEGUES et al. 2000).

Os pescadores artesanais trabalham sozinhos ou em conjunto com a família, as embarcações e aparelhagens utilizadas para pesca são bastante rudimentares, e muitos deles são fabricados a partir de espécies vegetais (Diegues, 1973). Essa interação corresponde à Etnobotânica que segundo Fonseca- Kruel e Peixoto (2004), pode ser descrita como o estudo das sociedades humanas, passadas e presentes, e suas inter-relações ecológicas, genéticas, evolutivas, simbólicas e culturais com as plantas.

Silvano (1997), ressalva que os pescadores artesanais possuem um conhecimento detalhado acerca da história natural, comportamental e classificação popular dos peixes, o qual é utilizado nas estratégias de pesca e pode ser útil para o manejo de estoques pesqueiros.

No Brasil, destacam-se os seguintes estudos envolvendo pescador artesanal: Sousa e Barrela (2001); Costa Neto, Dias e Mello (2002), Mourão e Nordi (2002); Begossi (2004), Santos e Santos (2005); Garcez e Sánches-Botero (2005), Pupo, Souto e Hanazaki (2006); Silva, Oliveira e Nunes (2007); El-Deir et al. (2012); Begossi et al. (2012), Santos et al. (2014), Zanchett (2015), Novaes et al. (2015), dentre outros. Segundo Pacheco (2003), a pesca artesanal é pouco estudada no território brasileiro e não há estatísticas precisas sobre tal atividade.

Diante desse cenário, a pesquisa foi desenvolvida com a finalidade de coletar informações etnobiológicas a respeito das artes e estratégias de pesca, produto pescado, e ainda descrever as técnicas utilizadas na construção e reparo de canoas da comunidade.

Com esse estudo, espera-se contribuir com a montagem de um banco de dados com informações a respeito das espécies zoológicas (peixes) de potencial utilitário, citadas pelos moradores; contribuição para ampliação das informações acerca dos conhecimentos sobre a etnobiologia da comunidade e compreender como este saber é distribuído na mesma; obtenção informações sobre as técnicas, modos e estratégias de pesca presentes na comunidade.

\section{REVISÃO BIBLIOGRÁFICA}

O saber das comunidades tradicionais foi por muito tempo desvalorizado pelos cientistas. A valorização do saber tradicional por parte dos etnobiólogos tem produzido alternativas para os paradigmas correntes, com efeitos benéficos para o conhecimento científico-acadêmico (POSEY, 1987).

A categoria tradicional de pescadores artesanais são aqueles que, na captura e desembarque de toda classe de espécies aquáticas, trabalham sozinhos e/ou utilizam mão-de-obra familiar ou não assalariada, explorando ambientes ecológicos localizados próximos à costa, pois a embarcação e aparelhagem utilizadas para tal possuem pouca autonomia (DIEGUES, 1973). 
As relações entre populações humanas e os recursos hídricos afetam de modo direto ou indireto todo o ecossistema, sobretudo no ambiente sob influência urbana quando tais relações devem ser consideradas nos planos de manejo dos recursos naturais. A integração de conhecimentos construídos pelos pescadores com os conhecimentos gerados pela ciência ocidental permite uma análise contextualizada, com olhar multidisciplinar, conectada à realidade dos pescadores (MONTENEGRO, NORDI E MARQUES, 2001).

Diegues e Arruda (2001) afirmam que a maioria dos estudos etnobiológicos com pescadores é realizada em comunidades que são, até certa proporção, isoladas em ambientes costeiros (açorianos e caiçaras) ou rurais. Diz ainda que povos como estes que são submetidos às pressões do capitalismo sofrem mudanças radicais, induzidas por externalidades, mas sempre criadas sob conceitos nativos.

Os trabalhos com pescadores artesanais realizados no Piauí foram: Amorim, 2010; Amorim; Barros, 2012; Sousa et al. 2012; Freitas et al. 2012; Meireles, 2012, Santos, 2013, Araújo (2013) e Nascimento, 2014. Estas comunidades, por sua vez, vêm chamando atenção dos etnobiólogos por apresentarem grande conhecimento sobre a atividade pesqueira artesanal, fauna/flora e relações ecológicas.

\section{MÉTODOS}

\section{1 Área e População de Estudo}

O município de União situa-se à margem direita do rio Parnaíba, com coordenadas 04 35' 09 "S e 42 51' 51" W e dista 59 km de Teresina. Contém uma população estimada em 42.654 habitantes, é um dos municípios mais antigos do Piauí. Para a sua formação, o coronel João do Rêgo Monteiro, Barão de Gurguéia, fez doações de terras marginando o rio Parnaíba, e nessas terras, foi sendo formado o primeiro núcleo de pescadores, cuja economia estava baseada na atividade pesqueira, que é realizada até os dias atuais (IBGE, 2014).

Com a finalidade de organizar e centralizar os direitos e deveres dos pescadores da região foi criada a Colônia Z-18 em 20 de maio de 2000, que está incorporada a Federação dos Pescadores do Estado do Piauí e possui 650 associados. Destes, apenas 300 pertencem ao município de União, enquanto que os demais estão distribuídos entre Lagoa Alegre/PI e algumas localidades do município de Caxias/MA.

A maioria dos pescadores de União reside nos bairros Beira Rio, São João e São Pedro, situados próximos ao rio Parnaíba, onde, grande parte das casas foi doada pelo governo Federal aos pescadores que perderam as suas residências em épocas de cheias.

O universo amostral da pesquisa para os levantamentos etnobiológicos foi de $50 \%$ do total de pescadores cadastrados na colônia pertencentes ao município de União, perfazendo 150 sujeitos, seguindo o preconizado por Barbeta (2006). O universo amostral estudado para analisar e descrever as técnicas utilizadas na construção e reparo de canoas da comunidade foram 10 pescadores artesanais, perfazendo $100 \%$ do total de construtores navais. Utilizou-se as faixas etárias sugeridas pelo IBGE (2014): jovens (entre 18 a 24 anos), adultos (entre 25 a 59) e idosos (a partir dos 60). 


\subsection{Coleta e Análise dos Dados}

As coletas de dados foram realizadas entre os meses fevereiro de 2012 a fevereiro de 2013, através de observação direta e com o auxílio de formulário padronizado com questões abertas e fechadas, através de entrevistas semiestruturadas propostas por (BERNARD, 1988). Tais entrevistas foram realizadas mediante permissão dos entrevistados através de aceite, conhecimento e assinatura do Termo de Consentimento Livre e Esclarecido (TCLE), em duas vias, uma pertencente ao entrevistado e outra ao pesquisador.

Foi utilizada a técnica da bola de neve (BAILEY, 1982), na qual os pescadores selecionados (maiores de 18 anos) foram visitados e entrevistados em seus domicílios, os quais indicaram outros pescadores a serem entrevistados. Posteriormente, as entrevistas foram transcritas em laboratório em conjunto com os dados referentes às conversas informais, registradas em diário de campo. Foi realizado registro fotográfico das canoas, materiais e equipamentos utilizados na fabricação das mesmas.

Os dados obtidos foram analisados de acordo com propostas qualitativas e quantitativas. Aos tratamentos estatísticos, foi criado um banco de dados no SPSS 20.0, em seguida construídos gráficos e tabelas nesse software. Foi utilizado o Excel para estruturar e organizar as tabelas.

Foi aplicado o índice de diversidade de Shannon-Wiener (MAGURRAN, 1988), com o objetivo de analisar a diversidade de citações entre gênero. O teste qui-quadrado (BUSSAB e MORETTIN, 2004) para analisar a diversidade de citações entre as faixas etárias, este, foi realizado juntamente com o teste da homogeneidade (FONSECA e MARTINS, 1996), devido aos tamanhos amostrais serem diferentes e as variáveis medidas serem sensíveis a este fator.

Foi utilizado o teste de Mann-Whitney para verificar o número de citações de espécies de peixes entre os gêneros e o método da correlação de Pearson com o objetivo de verificar o número de citações de espécies de peixes entre as faixas etárias (AYRES et al., 2007).

A coleta e identificação das espécies de peixes utilizados pela comunidade foram realizados paralelamente ao período das entrevistas. A obtenção de amostras do material zoológico obedeceu ao procedimento rotineiro de campo de acordo com a metodologia de Auricchio e Salomão (2002). Foram adicionados, também, aspectos relativos à localização das espécies zoológicas e botânicas coletadas, através do georeferenciamento.

A identificação do material zoológico foi efetuada através de bibliografia especializada, comparação de espécies depositadas no Laboratório de Zoologia Antônio João Dumbra, da Universidade Federal do Piauí (LZUFPI). Após identificação os peixes foram incorporados ao LZUFPI.

\section{RESULTADOS E DISCUSSÕES}

\subsection{Atividade Pesqueira, produto pescado e ecologia da pesca}

Dos 150 pescadores entrevistados, 55\% são do gênero masculino e $45 \%$ do feminino. 0 casal, filhos e agregados (genros, noras, sobrinhos, etc.) formam as famílias de pescadores artesanais dessa comunidade, por isso, mais de uma pessoa de uma mesma família, maior de 18 anos pode ter sido entrevistada. A participação das mulheres na pesca ocorre de forma direta 
(pescando com os maridos) ou indireta (beneficiando pescado/concertando ou fabricando aparelho de pesca).

Os pescadores artesanais de União estão distribuídos nas seguintes faixas etárias (Gráfico 1):

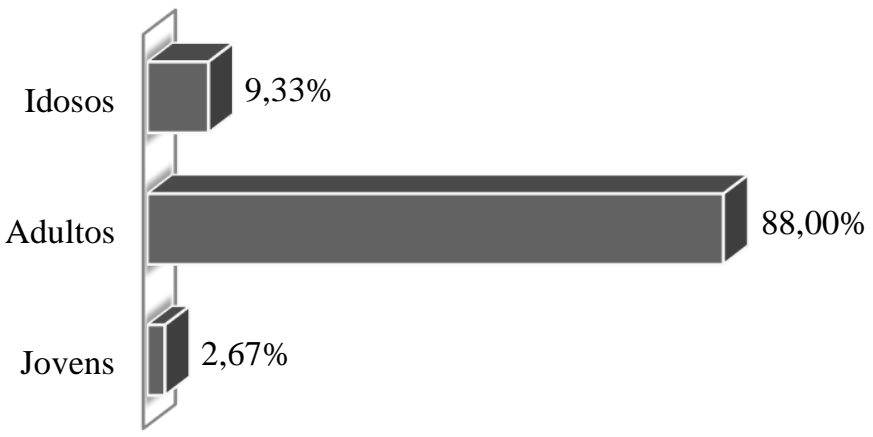

Gráfico 1: Distribuição da população de pescadores de União/PI, por faixa etária. Fonte: Pesquisa direta (2012- 2013).

A atividade pesqueira é realizada no rio Parnaíba e nas lagoas próximas da região, denominadas: Suapara, Calubi, Possi, Grande, Riacho da Raiz, Ininga, Tapera, João Freitas e Teresa, individualmente ou em parceria, reunidos em dupla ou em equipes. Parte do pescado é destinada a alimentação familiar e parte é vendida no mercado do peixe da cidade, situação também referida por Condini et al. (2007), Pieve, Miura e Rambo (2007), Burda e Schiavetti (2008) e Santos et al. (2014). Os dados mostram que a atividade pesqueira artesanal é destinada a obtenção de renda e sustento da família.

Quanto ao tempo de pesca (Gráfico 2), os pescadores estão distribuídos da seguinte maneira:

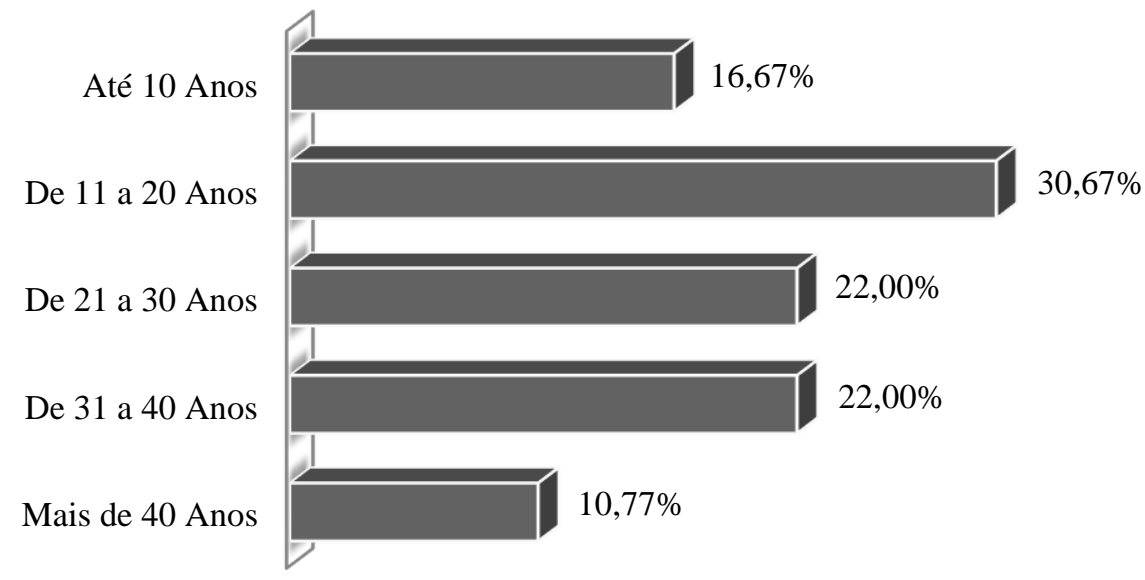

Gráfico 2: Distribuição da população em relação ao tempo de pesca da comunidade de pescadores artesanais de União/ PI, Brasil.

Fonte: pesquisa direta (2012- 2013).

Com os presentes dados, pode-se afirmar que praticamente durante toda a vida os entrevistados se utilizaram da pesca como principal atividade econômica. Rodrigues e Maia (2007), no município de Aquiraz (CE), revela uma maior representatividade de pescadores entrevistados na faixa etária entre 21 a 30 anos $(25,8 \%)$ e a menor estava entre os indivíduos de 41 a 50 anos (12,5\%). Em estudo realizado na Ponte dos Franceses (RS) (Harayashiki et al., 2011), a maior 
representatividade de pescadores de tarrafa foi encontrada na faixa etária entre 36 e 56 anos $(52,1 \%)$ e a menor entre os indivíduos entre 15 e 35 anos $(8,5 \%)$. Esses resultados sugerem que a pesca urbana vem sendo praticada cada vez mais por pessoas mais velhas.

As entrevistas mostraram que $22 \%$ dos pescadores não estão satisfeitos com a profissão, sendo a única causa relatada por eles a baixa renda mensal; $88 \%$ estão satisfeitos com a profissão, dentre eles, $44,00 \%$ afirmam que é da pesca onde tiram o sustento da família; $24,00 \%$ dizem realmente gostar da profissão; $10,00 \%$ relatam que foi a única profissão que teve oportunidade de aprender; $5,00 \%$ gostam por ser autônomo e, portanto só trabalham quando e onde querem e $5,00 \%$ não souberam responder.

Na captura dos peixes, utilizam variados instrumentos de pesca, que diferem de acordo com as espécies capturadas (Tabela 1 e 2): engancho (91,33\%), vara de pesca $(60,67 \%)$, tarrafa $(42,67 \%)$, currú $(14,67 \%)$, peneira $(6,67 \%)$, groseira $(6,00 \%)$, garrafa $(5,33 \%)$ e jiqui $(0,67 \%)$. Tais instrumentos são fabricados artesanalmente por $13,3 \%$ dos pescadores da Colônia. Isaac, Milstein e Ruffino (1996), em estudo realizado em Santarém/PA, citaram oito tipos de artefatos, os quais apenas a tarrafa foi um instrumento em comum com os citados em União. Netto, Nunes e Albino (2002), também correlacionaram artefato utilizado x produto pescado, citando a rede de espera como a mais utilizada. Os pescadores utilizam variados instrumentos de pesca porque a captura de diferentes peixes depende de diferentes técnicas.

Quanto ao conhecimento dos pescadores em relação à abundância das espécies, foram apontadas 10 espécies de peixes como sendo as mais raras (Tabela 1), e 15 espécies de peixes como sendo as mais comuns (Tabela 2).

Tabela 1: Espécies raras/artefatos utilizados na captura pelos pescadores artesanais da colônia Z-18, União/PI.

\begin{tabular}{|c|c|c|c|}
\hline Espécie & Nome Vulgar & \% Citada & Artefato de pesca utilizada na captura \\
\hline $\begin{array}{c}\text { Ageneiosus valenciennesi } \\
\text { Bleeker, } 1864 .\end{array}$ & Matrinchãn & $20,70 \%$ & engancho/tarrafa \\
\hline $\begin{array}{l}\text { Ageneiosus brevifilis } \\
\text { Valenciennes, } 1840 .\end{array}$ & Mandubé & $20,31 \%$ & engancho/tarrafa \\
\hline $\begin{array}{c}\text { Brachyplatystoma vaillantii } \\
\text { Valenciennes in Cuvier and } \\
\text { Valenciennes, } 1840 .\end{array}$ & Branquin & $14,89 \%$ & peneira/garrafa/vara de pesca \\
\hline $\begin{array}{l}\text { Sorubim limaBloch and } \\
\text { Schneider, } 1801 .\end{array}$ & bico-de-pato & $14,51 \%$ & engancho/tarrafa/groseira \\
\hline $\begin{array}{c}\text { Brachyplatystoma } \\
\text { filamentosum Lichtenstein, } \\
1819 .\end{array}$ & Piratinga & $7,54 \%$ & vara de pesca/tarrafa \\
\hline $\begin{array}{c}\text { Ogcocephalus vespertilio } \\
\text { Linnaeus, } 1758 .\end{array}$ & Caximbo & $7,35 \%$ & groseira/tarrafa/engancho \\
\hline $\begin{array}{c}\text { Pseudoplatystoma fasciatum } \\
\text { Linnaeus, } 1766 .\end{array}$ & Surubim & $4,64 \%$ & engancho/groseira/tarrafa \\
\hline $\begin{array}{c}\text { Pseudoplatystoma corruscans } \\
\text { Spix and Agassiz, } 1829 .\end{array}$ & Pintado & $3,68 \%$ & tarrafa/enganchogroseira \\
\hline $\begin{array}{c}\text { Plagioscion } \\
\text { squamosissimusHeckel, } 1840 .\end{array}$ & Curvina & $3,68 \%$ & engancho/tarrafa/vara de pesca \\
\hline $\begin{array}{c}\text { Potamotrygon signata } \\
\text { German, } 1913 .\end{array}$ & Arraia & $2,70 \%$ & currú \\
\hline Total & $100 \%$ & & \\
\hline
\end{tabular}

Fonte: Pesquisa Direta, Julho/2012. 
Tabela 2: Espécies comuns/artefatos utilizados na captura pelos pescadores artesanais da colônia Z-18, de União/PI.

\begin{tabular}{|c|c|c|c|}
\hline Espécie & Nome Vulgar & \% Citada & Artefato de pesca utilizada na captura \\
\hline Prochilodus lacustris Steindachner, 1907. & Curimatá & $13,08 \%$ & engancho/tarrafa \\
\hline $\begin{array}{l}\text { Psectrogaster rhomboides Eigenmann } \\
\text { and Eigenmann, } 1889 .\end{array}$ & Branquinha & $10,69 \%$ & vara de pesca/Peneira/garrafa \\
\hline $\begin{array}{l}\text { Leporinus friderici Bloch, } 1794 \text { e } \\
\text { Schizodon fasciatus Spix and Agassiz, } \\
1829 .\end{array}$ & Piau & $8,72 \%$ & vara de pesca/currú/garrafa \\
\hline $\begin{array}{l}\text { Geophagus brasiliensis Quoy and } \\
\text { Gaimard, } 1824 .\end{array}$ & Cará & $8,58 \%$ & engancho/tarrafa \\
\hline $\begin{array}{l}\text { Triportheus angulatus Spix and Agassiz, } \\
1829 .\end{array}$ & Sardinha & $7,59 \%$ & $\begin{array}{l}\text { vara de pesca/Jiqui/ } \\
\text { peneira/currú/garrafa }\end{array}$ \\
\hline Pygocentrus nattereri Kner, 1858. & Piranha & $7,45 \%$ & vara de pesca/jiqui/ peneira/garrafa \\
\hline Oreochromis niloticus Linnaeus, 1758. & Tilapia & $7,31 \%$, & engancho/vara de pesca \\
\hline Hoplias malabaricus Bloch, 1794. & Traíra & $6,89 \%$ & vara de pesca/currú/garrafa \\
\hline Colossoma macropomum Cuvier, 1816. & Tambaqui & $6,19 \%$, & engancho/tarrafa \\
\hline Pimelodus maculatus Lacepède, 1803. & Mandi & $4,78 \%$ & $\begin{array}{c}\text { engancho/vara de } \\
\text { pesca/peneira/currú/garrafa }\end{array}$ \\
\hline $\begin{array}{l}\text { Cichla ocellaris Bloch and Schneider, } \\
1801 .\end{array}$ & Tucunaré & $4,78 \%$ & engancho/tarrafa \\
\hline Metynnis sp & Pacu & $4,08 \%$ & vara de pesca/peneira \\
\hline $\begin{array}{l}\text { Hypostomus plecostomus Linnaeus, } \\
1758 .\end{array}$ & Bodó & $3,94 \%$, & vara de pesca/tarrafa \\
\hline $\begin{array}{l}\text { Pellona castelnaeana Valenciennes in } \\
\text { Cuvier and Valenciennes, } 1847 .\end{array}$ & Arenga & $3,52 \%$ & engancho/tarrafa \\
\hline $\begin{array}{l}\text { Hemiodus parnaguae Eigenmann and } \\
\text { Henn, } 1916 .\end{array}$ & Frecheiro & $2,40 \%$ & engancho/tarrafa \\
\hline Total & & $100 \%$ & \\
\hline
\end{tabular}

Fonte: Pesquisa Direta, Julho/2012.

O engancho é uma rede de espera, em formato retangular, confeccionada com linha de nylon (também conhecida como linha americana), isopor e chumbo. É colocada geralmente por dois homens em locais rasos do rio onde fica por aproximadamente 24 horas. Sua função é capturar peixes de tamanhos grandes que ficam presos entre os espaços existentes entre um nó e outro do instrumento.

A tarrafa é um instrumento em forma de cone, com pequenos pesos de chumbo distribuídos ao redor de toda a circunferência da malha, utilizada principalmente na captura de peixes grandes. É arremessada ao rio com as mãos, ao entrar em contato com a água, a rede afunda, e em seguida, o pescador a puxa, enroscando assim os peixes na malha.

A vara de pesca é uma peça simples formada de bambu (Bambusa sp) ou ferro, linha de nylon e um pequeno gancho de ferro em sua ponta, onde é colocado a isca. Com ela, capturam-se poucos peixes, e em geral de pequeno porte.

O jiqui é confeccionado com madeira e plástico, tem forma de cubo e no seu interior é colocada à isca para então haver a entrada e a captura dos peixes.

A groseira é um instrumento de várias linhas com ganchos nas pontas dispostos sobre uma linha central, utilizado na captura de peixes grandes. 
A peneira é um instrumento em forma de círculo, em geral com 1,30 $\mathrm{m}$ de altura por 1,0 m do comprimento. É confeccionada com talo de tabocas secas (Bambusa sp.), e sua parte central tem formato de tranças com espaços pequenos entre elas por onde passa a água. A pesca com esse artefato pode ser realizada nas margens do rio e geralmente o pescado capturado tem tamanho pequeno.

O currú é um instrumento cônico, na forma de um funil invertido, aberto na extremidade superior e inferior, para sua utilização, a boca do instrumento (parte mais fechada) é agarrada pelas duas mãos do pescador, em seguida o instrumento é colocado sobre a água rasa até tocar o solo e o pescado apreendido é tirado pela abretura superior do instrumento.

A pesca com garrafas de vidro, ou "pet" é pouco difundida na colônia. São utilizadas na captura de peixes pequenos e utilizam como isca a farinha de mandioca (Manihot esculenta Crantz) ou côco (Cocus nucifera L.) ralado no interior das mesmas. Quando retirada traz em seu interior uma grande quantidade de peixes de pequeno porte.

Não houve diferenças significativas quanto ao uso dos instrumentos de pesca pelos homens e mulheres da colônia: homens - engancho $(98,78 \%)$, vara de pesca $(52,44 \%)$ e tarrafa $(43,90 \%)$ e mulheres - engancho (82,35\%), vara de pesca $(70,59 \%)$ e tarrafa $(41,18 \%)$. O uso do engancho, também conhecido como rede de espera foi observado no estudo de Pieve, Miura e Rambo (2007), o qual foi citado por todos os pescadores, sendo utilizado tanto para captura de peixes, como para a captura de camarão e siri. Netto, Nunes e Albino (2002) e Pinheiro e Joyuex (2007), também citaram o uso de redes nas comunidades estudadas por eles. Segundo Hanazaki (1997), em Ponta do Almada, Ubatuba/SP e Clauzet, Ramires e Barrella (2005), em Barra do Una e Enseada do Mar Virado/SP, a rede de espera foi a técnica mais citada nas três comunidades caiçaras. Essa técnica é a mais utilizada por conta do maior numero de peixes capturados.

O uso de tarrafas e vara de pesca ou (anzol) também foram citados nos estudos de Costa Neto e Marques (2001), Chaves e Robert (2003), Cotrim (2008), e Harayashiki et al. (2011), porém Machado et al. (2010), afirmam que nas comunidades estudadas, a tarrafa obteve um percentual mínimo de utilização.

Os pescadores artesanais de União afirmaram que o melhor horário para realização da atividade pesqueira é no período da noite com $(41,33 \%)$ das citações, pois nesse horário não há a presença dos raios solares que tanto agridem a pele. Um percentual de 30,67\% prefere o início da manhã; $15,33 \%$ pescam preferencialmente à tarde e 12,67\% de madrugada. Porém, Pinheiro e Joyeux (2007), identificaram a pesca em horários que dependem do peixe que se quer pescar.

Todos os pescadores entrevistados afirmaram conhecer e respeitar a época da piracema (período de 15 de novembro a 16 de março). Quando indagados sobre os meses em que há mais disponibilidade de peixes, $60,67 \%$ afirmaram ser o mês de maio; $29,33 \%$ junho e $10 \%$ julho. Ou seja, os meses posteriores ao período de proibição da pesca.

O legado da profissão é transmitido de geração em geração, na maioria das vezes pelo contato direto que as crianças/ jovens têm com a pesca, pois geralmente mais de uma pessoa da família já é pescador e por isso fica fácil a aprendizagem das técnicas de pesca. $78 \%$ dos entrevistados afirmaram ter até duas pessoas que também pescam na família, 11,33\% dizem ter entre três e cinco pessoas e 10,67\% mais de cinco. Garcez e Sánches-Botero (2005), relatam que no Rio Grande do Sul, os conhecimentos acerca da pescaria são passados de pai para filho, 
perpetuando famílias de pescadores, como também observado por Hanazaki (1997), onde mais da metade dos entrevistados em Ponta do Almada, Ubatuba/SP, são filhos de pais pescadores. Clauzet, Ramires e Barrella (2005), em Barra do Una e Enseada do Mar Virado/SP mostram que a atividade pesqueira é desenvolvida por diferentes gerações, nas duas comunidades estudadas. Os dados mostram que a cultura pesqueira é transmitida ao longo das gerações.

\subsection{Conhecimentos Etnozoológico por gênero e faixa etária}

Com relação à diversidade de citações entre gêneros foi observado valor semelhante entre homens e mulheres, refletindo que o conhecimento está bem distribuído, não havendo, portanto, diferenças significativas comprovadas através do índice de Shanon, homens $\left(H^{\prime}=3,053\right)$ e mulheres $\left(H^{\prime}=3,095\right)$. Esse resultado pode estar relacionado, tanto ao fato de mulheres e homens participarem diretamente da pesca, como pelo compartilhamento de conhecimento tradicional, já que homens e mulheres atuam em sistema de parceria na atividade pesqueira. Diferentemente de outros trabalhos como os de Maikhuri e Gangwar (1993), Guijt (2005) e Sousa (2010), onde apontam um maior conhecimento tradicional entre os grupos masculinos por estarem ligados diretamente ao setor produtivo ou por maior contato com a natureza, restando para as mulheres os serviços domésticos ou o papel materno.

Quanto à diversidade de citações entre faixas etárias, apenas os jovens possuem menos conhecimento do que adultos e idosos. Estes, no entanto não diferem entre si significativamente. O conhecimento, portanto, encontra-se distribuído irregularmente entre as faixas etárias.

Esse resultado deve-se ao fato dos jovens participarem com menos frequência na pescaria, pois estes dividem essa atividade com outras, a exemplo da escola. Adultos e idosos foram os grupos detentores do conhecimento. O primeiro grupo pelo fato de estarem mais abertos a diálogos e participam com mais frequência na atividade pesqueira, além do conhecimento que foi recebido dos mais velhos. E o segundo grupo, praticamente toda a vida tiveram a pesca como principal atividade de subsistência, e isso os proporcionaram um acúmulo muito grande de saber.

Quanto a correlação entre sexo e número de peixes citados, a média alcançada pelas categorias foi muito próxima (homens $=8,34$ ) e (mulheres $=8,00$ ), o teste foi realizado com um intervalo de confiança de $95 \%$, e o $p$ valor atingido foi de $(p=0,416)$, admitindo-se $p<0,05$. Sendo, portanto, um valor não significativo, ou seja, não existe diferença significativa entre o numero de citações entre homens e mulheres (Gráfico 3). Diferentemente do trabalho de Batistella, Castro e Vale (2005), no Lago Janauacá/AM, onde verificaram que há diferenças significativas no conhecimento tradicional, sendo este presente com maior intensidade na classe masculina.

O coeficiente de Pearson mostrou que a relação entre a idade e o número de peixes conhecidos atingiu um valor de $(r=-0,62)$, sendo, portanto, a correlação considerada moderada negativa. Em outras palavras, a idade não influenciou no número de peixes citados por cada classe. 


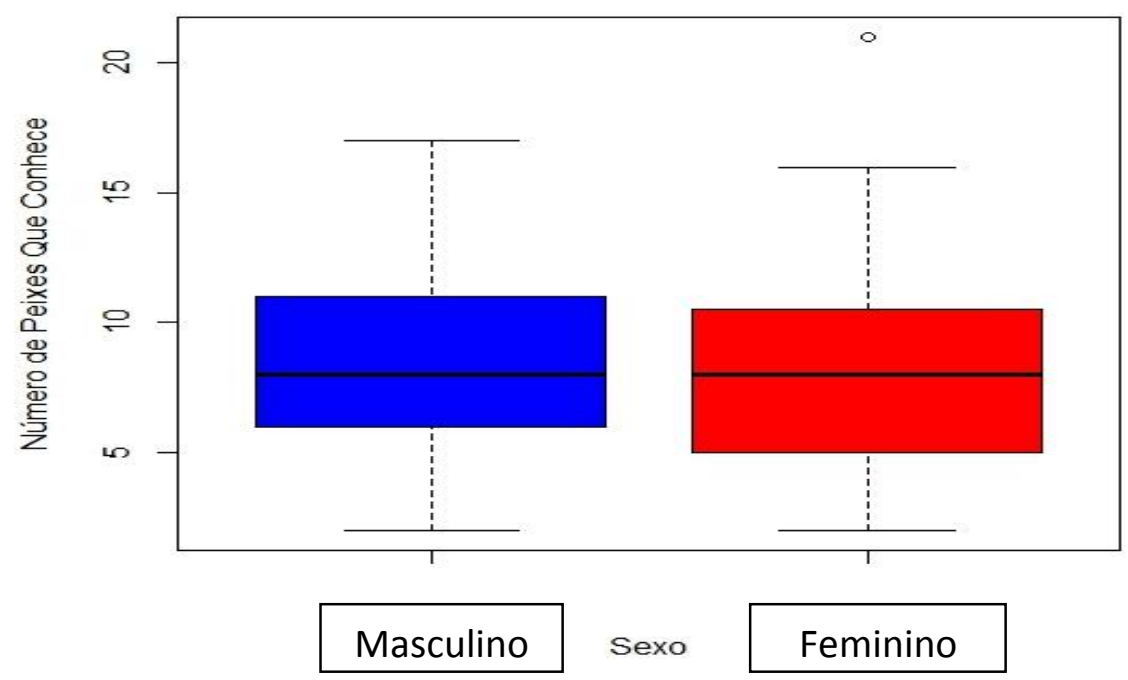

Gráfico 3: Comparação entre o número de citações de espécies de peixes entre homens e mulheres da comunidade de pescadores artesanais de União/PI.

O coeficiente de Pearson mostrou que a relação entre a idade e o número de peixes conhecidos atingiu um valor de $(r=-0,62)$, sendo, portanto, a correlação considerada moderada negativa. Em outras palavras, a idade não influenciou no número de peixes citados por cada classe.

\subsection{Construção e reforma das embarcações em União, PI}

A construção e a reforma das canoas são realizadas por 10 pescadores o que corresponde a 6,67\% dos entrevistados. A construção é feita na sede da Colônia Z-18 e dura em média uma semana. O conhecimento dessa atividade foi transferido no núcleo familiar e por ser uma arte que requer força e habilidade com instrumentos cortantes, é ensinada apenas para os homens da família.

O material botânico utilizado se resume a quatro espécies de plantas: pau-d arco (Tabebuiaspp), cedro (Cedrella odorata L.), imbiratanha (Pseudobombax marginatumA.St-Hil., Juss. \& Cambess) A. (Robyns) e breu (Protium ssp) madeira vermelha vinda do Pará. Segundo os informantes, essas plantas não são mais encontradas na margem do rio Parnaíba, onde se situa o município de União, isso se deve ao fato da constante procura pela matéria prima, portanto elas foram se tornando cada vez mais escassas, e para adquiri-las é preciso navegar até a outra margem onde fica o estado do Maranhão, ou ainda comprá-las em madeireiras. Assim, nossos resultados contrastam com o que foi observado em reservatórios das regiões Sul e Sudeste do Brasil, onde os pescadores artesanais usam principalmente embarcações de alumínio e motor (Minte-Vera e Petrere Jr., 2000; Petrere Jr. et al., 2006; Alves Da Silva et al., 2009; Maruyama et al., 2009; Novaes e Carvalho, 2009; Novaes e Carvalho, 2011; Schork et al., 2012). Duas hipóteses podem explicar essas diferenças: (i) a falta de acesso a esse tipo de equipamento pelos pescadores. (ii) elevado custo dos equipamentos.

Segundo as informações coletadas, as canoas são divididas em sete partes (Figura 1): proa, popa, cintado, forro, cavernas, banco de sentar e remo. 


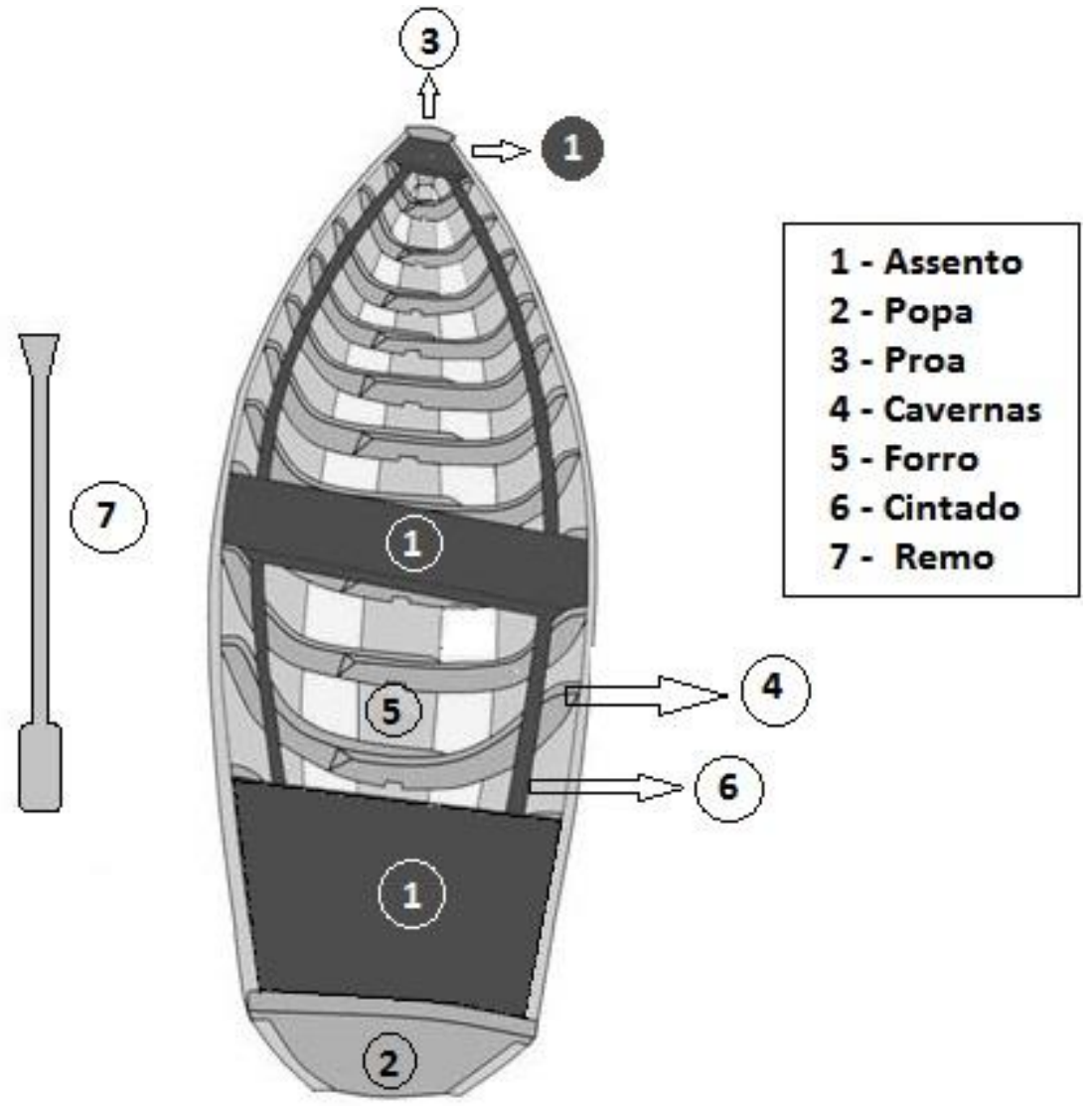

Figura 1: Representação gráfica da canoa fabricada em União/PI. Fonte: Elaboração Própria.

Para fabricação da proa é utilizada o breu. O cintado é feito com a utilização do pau-d'arco. Para a construção do forro, utilizam o cedro e a raspa da casca da imbiratanha cuja função desta última é preencher os espaços existentes entre uma peça de madeira e outra. As cavernas são estruturas em forma de $U$, cujo conjunto forma o cavernante; cada estrutura é formada por duas partes, uma direita e outra esquerda, há geralmente 11 pares por barco e sua construção é feita com pau-d’arco.

A popa é fabricada com a utilização do breu. Os bancos geralmente são em números de três, é feita com pau-d`arco, que também é utilizado na construção dos remos geralmente um par.

Para a construção ou reforma das canoas são utilizadas algumas ferramentas: serrote, enchó- serve para lavrar a madeira, prana - utilizada para deixar a madeira lisa e uniforme, pregos, furadeira, espátula - utilizada para arrancar pregos e tábuas, martelo e régua.

As canoas fabricadas seguem um padrão que varia de 4 a $5 \mathrm{~m}$ de comprimento, (medição feita do início da proa até o fim da popa), sob um metro de largura (medição feita entre um lado ao outro do casco da parte central da canoa). Apesar das canoas apresentar diferentes tamanhos, a confecção das mesmas é feita com a mesma matéria prima botânica.

Em algumas canoas, utilizam motores de pequeno porte e potência na região da popa, e as embarcações possuem pouca autonomia para os deslocamentos. Situação também observada no trabalho de Amorim (2010), cujas canoas fabricadas no Poti Velho, Teresina/PI, também possuíam motores de baixa potência. Silva, Oliveira e Nunes (2007), constataram que $90 \%$ dos pescadores de Conceição do Araguaia/PA usam uma canoa chamada de rabêta que possui em média 5 a $7 \mathrm{~m}$ 
de comprimento, movida a motor. Cardoso et al. (2008), em estudo com comunidades de pescadores na região do Rio Grande do Sul, constataram que em Rio Pardo as embarcações utilizadas são $59 \%$ barcos a motor e $41 \%$ canoas a remo. Em Cruzeiro do Sul, $82 \%$ dos pescadores utilizam barcos a remo e apenas $18 \%$, o equivalente a dois pescadores, usam barcos a motor. Em Cachoeira do Sul, nove dos 22 entrevistados pescam com embarcação a motor.

Abril, maio e junho foram os meses citados como a época em que há maior procura para construção das canoas; nesse período de tempo, são construídas em média quatro canoas mensais, e nos demais meses a produção é reduzida. As canoas duram em média um ano, após esse período elas devem ser renovadas.

As canoas novas são vendidas por $\mathrm{R} \$ 1.300,00$ (um mil e trezentos reais) (em 2013) e a média de renda obtida pela atividade é $\mathrm{R} \$ 560,00$ por canoa. O custo de uma canoa em União é alto quando comparado às outras localidades: Meireles (2012) retrata que na comunidade pesqueira Canárias, Delta do Parnaíba/PI, a média de preço para a construção de uma embarcação de tamanho médio é de $\mathrm{R} \$ 500,00$ pela mão de obra e $\mathrm{R} \$ 700,00$ de materiais e projeto. Costa Neto e Marques (2001) afirmam que os pescadores da comunidade de Siribinha, município de Conde/BA preferiam comprar canoas a jangada, pois as canoas custam em média $R \$ 100,00$, enquanto que uma jangada não ficava por menos de $\mathrm{R} \$ 350,00$ a $\mathrm{R} \$ 400,00$ e de acordo com o perfil do setor pesqueiro desenvolvido pela Secretaria de Agricultura do Estado da Bahia (Bahia, 1994), canoas e barcos a remo, representavam $64,9 \%$ do total de embarcações em atividade no estado, acarretando a exploração dos recursos mais próximos à costa.

\section{CONCLUSÕES}

Os pescadores artesanais de União/PI possuem um vasto conhecimento em relação a atividade pesqueira, esta, é a principal atividade de subsistência realizada na comunidade. Os conhecimentos etnobiológicos sobre a pesca são transmitidos de geração a geração, pela oralidade e prática diária.

Os pescadores possuem um conhecimento detalhado acerca da dinâmica dos peixes, a relação artefato de pesca e produto pescado e ainda sobre o período da proibição da pesca. 0 período da piracema é respeitado por todos os pescadores.

A pesquisa mostra que não existem diferenças significativas entre o numero de citações de peixes por homens/mulheres, porém quando comparado as faixas etárias, os jovens possuem menos conhecimento do que adultos e idosos. Estes, no entanto não diferem entre si significativamente. O conhecimento, portanto, encontra-se concentrado nas pessoas com mais anos de experiências na pesca.

A prática da pesca é realizada tanto por mulheres, quanto por homens, demonstrando que a mulher pescadora além de admitir o papel principal de cuidar da família, assumiu seu posto de trabalhadora, auxiliando na renda familiar.

São vários os instrumentos de pesca utilizados, que diferem entre si quanto ao tipo de peixe que se deseja capturar, porém o engancho ganha o enfoque maior, pois é o único que consegue capturar uma quantidade relativamente grande de peixes, quando comparado aos demais instrumentos. 
A construção e o reparo das canoas é uma atividade restrita aos homens, pelo fato de exigir muita força física. Além de auxiliar na renda familiar, esta atividade é de fundamental importância para perpetuação da atividade pesqueira.

A atividade pesqueira artesanal praticada em União/PI, não é apenas uma forma de obtenção de renda, mas um meio de vida importante que precisa ser preservado, realizado por um grupo cultural ansioso para se capacitar, para negociar, gerenciar, e cuidar do recurso pesqueiro, contribuindo para a sociedade de forma sustentável.

\section{REFERÊNCIAS}

1. ALVES DA SILVA, M.E.P.; CASTRO, P.M.G.; MARUYAMA, L.S.; PAIVA, P. Levantamento da pesca e perfil socioeconômico dos pescadores artesanais profissionais no reservatório Billings. Boletim do Instituto de Pesca, 35(4): p. 531-543, 2009.

2. AMORIM, A.N. Etnobiologia da comunidade de pescadores artesanais urbanos do bairro Poti Velho, Teresina/PI, Brasil. Teresina, 2010. Dissertação (Mestrado) - Programa de Pós Graduação em Desenvolvimento e Meio Ambiente, Universidade Federal do Piauí, 122p. 2010.

3. AMORIM, A.N.; SILVA, M.P.; BARROS, R.F.M. Plantas cultivadas em quintais: um comparativo entre urbano e rural. In: ROCHA, J. R. S.; BARROS, R. F. M.; ARAUJO, J. L. L. (Org.). Sociobiodiversidade no Meio Norte brasileiro. 7ed.Teresina: EDUFPI, v. 1, p. 193-204. 2012.

4. ARAUJO, M. P. Etnobiologia da Comunidade pesqueira Passarinho, llha das Canárias, Reserva Extrativista Marinha do Delta do Parnaíba, Araioses, MA, Brasil. Dissertação (Mestrado em Desenvolvimento e Meio Ambiente) - Programa de Pós- Graduação em Desenvolvimento e Meio Ambiente. Universidade Federal do Piauí, 134f. 2013.

5. AURICCHIO, P.; SALOMÃO, M.G. Técnicas de coleta e preparação de vertebrados para fins científicos e didáticos. Rio de Janeiro: Papel Virtual, 348p, 2002.

6. AYRES, M. et al. BioEstat 5.0: Aplicações estatísticas nas áreas das ciências biológicas e médicas. Sociedade civil Mamirauá, Belém, CNPq, Brasília, 2007.

7. BAILEY, K. D. Methods of social research. New York: McMillan Publishers, The free press, 553p. 1982.

8. BARBETA, P. A. Estatística aplicada as Ciências Sociais. 6. ed. Editora: UFSC, 2006.

9. BATISTELLA. A.M.; CASTRO, C.P., VALE, J.D. Conhecimento dos moradores da comunidade de Boas Novas, no Lago Janauacá - Amazonas, sobre os hábitos alimentares dos peixes da região. Acta Amazônica, v. 35 (1), p.51 - 54. 2005.

10. BEGOSSI, A. Ecologia de pescadores da Mata Atlântica e da Amazônia. São Paulo: Hucitec, 332 p. 2004.

11. BEGOSSI, A. et al. Compensation for environmental services from artisanal fisheries in SE Brazil: Policy and technical strategies. Ecological Economics, p. 25-32. 2011.

12. BEGOSSI, A. et al. The paraty artisanal fishery (southeastern Brazilian coast): ethnoecology and management of a social-ecological system (SES). Journal of Ethnobiology and Ethnomedicine, 8:22. 2012.

13. BERNARD, H.R. Research Methods in Cultural Anthropology. Sage. Newbury Park, CA, 
EEUU.520 p. 1988.

14. BURDA, A.; SCHIAVETTI, A. Análise ecológica da pesca artesanal em quatro comunidades pesqueiras da Costa de Itararé, Bahia, Brasil: Subsídios para a gestão Territorial. Revista da Gestão Costeira Integrada, 8 (2) ,p.149-168. 2008.

15. BUSSAB, W.O.; MORETTIN, P.A. Estatística Básica. Editora Saraiva, 2004.

16. CARDOSO, E. S. et al. Pesca e Atividades Complementares. In: 23 Jornada Acadêmica Integrada, Santa Maria. Resgatando o passado e projetando o futuro. Santa Maria: PRPGP UFSM, p. 1-2. 2008.

17. CHAVES, P. de T.; BOBERT, M. de C. Embarcações, artes e procedimentos da pesca artesanal no litoral sul do estado do Paraná, Brasil. Atlântica, 25 (1). p. 53- 59. 2003.

18. CLAUZET, M.; RAMIRES, M.; BARRELLA, W. Pesca artesanal e conhecimento local de duas populações caiçaras (Enseada do Mar Virado e Barra do Una) no litoral de São Paulo, Brasil. Revista Multiciência. no. 4, 22p. Maio de 2005.

19. COSTA-NETO, E.M.; MARQUES, J.G.W. Atividades de pesca desenvolvidas por pescadores da comunidade de Siribinha, município de Conde, Bahia: Uma abordagem etnoecológica. Sitientibus, 1 (1). p. 71- 78. 2001.

20. COSTA-NETO, E. M.; DIAS, C. V.; MELO, M. N. O conhecimento ictiológico tradicional dos pescadores da cidade de Barra, região do médio São Francisco, Estado da Bahia, Brasil. Acta Scientiarum, v.24, n.2, p. 561-572. 2002.

21. COTRIM, D.S. Agroecologia, sustentabilidade e os pescadores artesanais: $O$ caso de Tramandaí (RS). Porto Alegre, 2008. Dissertação (Mestrado) Programa de Pós - Graduação em Desenvolvimento rural - Universidade Federal do Rio Grande do Sul, Porto Alegre, 197p. 2008.

22. DIEGUES, A.C. (Org.). Os saberes tradicionais e a biodiversidade no Brasil. São Paulo: MMA/NUPAUB, 2000.

23. DIEGUES, A.C. Diversidade biológica e culturas tradicionais litorâneas: $\mathbf{O}$ caso das comunidades caiçaras. São Paulo: NUPAUB-USP, 22p. 1988.

24. DIEGUES, A.C. Pesca e marginalização no litoral paulista. São Paulo, 1973. Dissertação (Mestrado) - NUPAUB; CEMAR, Universidade de São Paulo, São Paulo, 187 p. 1973.

25. DIEGUES, A.C.; ARRUDA, R.S.V. (Org.). Saberes tradicionais e biodiversidade no Brasil. Brasília: Ministério do Meio Ambiente. (Biodiversidade, 4) 2001.

26. EL-DEIR, A.C.A. et al.. Ichthyofauna Used in Traditional Medicine in Brazil. Hindawi Publishing Corporation. Evidence-Based Complementary and Alternative Medicine. p. 1-16. 2012.

27. FONCESA- KRUEL, V.S.; PEIXOTO, A.L. Etnobotânica na reserva extrativista marinha de Arraial do Cabo, RJ, Brasil. Acta Botânica Brasilica, v. 18, no 1, p. 1777-190. 2004.

28. FONSECA, J.S.; MARTINS. Curso de Estatística - 6ạ edição. São Paulo: Atlas, 1996.

29. FREITAS, S.T.; PAMPLIN, P.A.Z.; LEGAT, J.; FOGAÇA, F.H.S.; BARROS, R.F.M. Conhecimento tradicional das marisqueiras de Barra Grande, Área de Proteção Ambiental do Delta do Parnaíba, Piauí, Brasil. Ambiente \& Sociedade, v. 15, n. 2, p. 91-112, 2012.

30. GARCEZ, D.S.; SÁNCHES-BOTERO, J.I. Comunidades de Pescadores Artesanais no Estado do Rio Grande do Sul, Brasil. Atlântica, Rio Grande, 27 (1), p.17-29, 2005. 
31. GLÁRIA, V. Sujetos colectivos en búsqueda de sustentabilidad pesquera: relatos de los miembros de una comunidad de pescadores artesanales, $\mathrm{V}$ región, Chile. Revista de la Universidad Bolivariana, v.9 (27), 2010.

32. GUIJT, I. Gender and participation: bridging the gap. Development and gender in Brief. BRIDGE / IDS, n. 9. Institute of Development Studies, University of Sussex, Brighton, United Kingdom. 2005.

33. HANAZAKI, N. Conhecimento e uso de plantas, pesca e dieta em comunidades caiçaras do município de Ubatuba (SP). São Paulo, 1997. Programa de Pós - Graduação em Ecologia, Universidade de São Paulo, São Paulo, 136p. 1997.

34. HARAYASHIKI, C.A.Y.; FURLAN, F.M.; VIEIRA, J.P. Perfil sócio-econômico dos pescadores da Ponte dos Franceses, Rio Grande, RS, Brasil. Boletim do Instituto de Pesca, 37(1): 93-101. 2011.

35. IBGE. Instituto Brasileiro de Geografia e Estatística. 2014. Disponível em: <http://www.ibge.gov.br/cidadesat/topwindow.htm?1> acesso em 20 Dezembro. 2014.

36. ISAAC, V.J; MILSTEIN, A.; RUFFINO, M.L. A pesca artesanal no baixo amazonas: análise multivariada da captura por espécie. Acta Amazonica. 26 (3). p. 185-208. 1996.

37. KIDO- CRUZ, M.T. Análisis comparativo de La calidad de vivenda de los pescadores ribereños según el tipo de pesca em el sur del pacífico mexicano. Trópico Húmedo, 24(2). p. 163-173. 2008.

38. MACHADO. T.M. et al. Fatores que afetam a qualidade do pescado na pesca artesanal de municípios da costa sul de São Paulo, Brasil. Boletim do Instituto de Pesca, São Paulo, 36(3). p. 213-223, 2010.

39. MAGURRAN, A.E. Ecological diversity and its measurement. Princeton University Press, New Jersey. 1988.

40. MAIKHURI, R.K., GANGWAR, A.K. Ethnobiological notes on the Khasi and Garo tribes of Meghlaya, northeast India. Economic Botany. p. 345-357. 1993.

41. MARUYAMA, L.; CASTRO, P.M.G.; PAIVA, P. Pesca artesanal no médio e baixo Tietê, São Paulo, Brasil: aspectos estruturais e socioeconômicos. Boletim do Instituto de Pesca, 35(1): 61-81. 2009.

42. MEIRELES, V. de J.S. Etnobotânica e etnozoologia da comunidade pesqueira Canárias, Reserva Extrativista Marinha do Delta do Parnaíba, Nordeste, Brasil. Teresina, 2012. Dissertação (Mestrado) Universidade Federal do Piauí, 2012.

43. MINTE-VERA, C.V. e PETRERE JR., M. Artisanal fisheries in urban reservoirs: a case study from Brazil (Billings Reservoir, São Paulo Metropolitan Region). Fisheries Management and Ecology, 7(4): 537-549. 2000.

44. MONTENEGRO, S.C.S.; NORDI, N.; MARQUES, J.G.W. Contexto cultural, ecológico e econômico da produção e ocupação dos espaços de pesca pelos pescadores de tipu (Macrobrachium carcinus) em um trecho do bairro São Francisco, Alagoas- Brasil. Interciência, v. 26, n. 11, p. $535-540,2001$.

45. MORI, L.A. et al. Manual de manejo do herbário fanerogâmico. Centro de pesquisa do Cacau: Ilhéus, 1989. 
46. MOURÃO, J.S; NORDI, N. Comparações entre as taxonomias folk e científica para peixes do estuário do rio mamamguape, Paraíba, Brasil. Interciencia. asociación Interciencia, Caracas, Venezuela. Diciembre, ano/v. 27, no 12, p.664-668.2002.

47. NASCIMENTO, M.G.P. Etnobotânica e Etnozoologia em Comunidades Pesqueiras de Parnaíba E Cajueiro da Praia, Piauí. Teresina, 2014. Dissertação de mestrado. Universidade Federal do Piauí. Pg: 157. 2014.

48. NETTO, R. de F.; NUNES, A.G.A.; ALBINO, J. A pesca realizada na comunidade de pescadores artesanais de Santa Cruz/ES- Brasil. Boletim do Instituto de Pesca, v. 28, no1, p. 93- 100, 2002.

49. NOVAES, J.C.L.; CARVALHO, E.D.B. Recursos pesqueiros oriundos da pesca artesanal no reservatório de Jurumirim, Rio Paranapanema, Alto Paraná, Brasil. Boletim do Instituto de Pesca, São Paulo, 35: 553-565. 2009.

50. NOVAES, J.L.C. А.; CARVALHO, E.D.в. Artisanal fisheries in a Brazilian hypereutrophic reservoir: Barra Bonita Reservoir, Middle Tietê River. Braz. J. Biol., vol. 71, no. 4, p. 821-832. 2011.

51. NOVAES, J.L.C.; FREIRE, A.E.; AMORIM, R.A.; COSTA, R.S. Diagnóstico da pesca artesanal em um reservatório do semiárido brasileiro. Boletim do Instituto de Pesca, São Paulo, 41(1): 31 42, 2015.

52. PACHECO, C.B. Meio ambiente. Pesquisa traça perfil da pesca artesanal em comunidade de pescadores do litoral de São Paulo. 2003. Disponível em <http://www.usp.br/agen/repgs/2003/pags/082.htm>. Acesso em 22 janeiro de . 2013.

53. PACHECO, R.S. Aspectos da ecologia de pescadores residentes na península de Maraú - BA: pesca, uso de recursos marinhos e dieta. Brasília, 2006. Dissertação (Mestrado) - Programa de Pós- Graduação em Ecologia, Universidade de Brasília, Brasília, 68p. 2006.

54. PETRERE JR., M.; WALTER, T.; MINTE-VERA, C.V. Income evaluation of small-scale fishers in two Brazilian urban reservoir: represa Billing (SP) and Lagoa Paranoá (DF). Brazilian Journal of Biology, 66(3): 817-828. 2006.

55. PIEVE, S.M.N; MIURA, A.K; RAMBO, A.G. A pesca artesanal na colônia São Pedro (Z-3), Pelotas, RS. Anais... XLV Congresso da Sober "Conhecimento para Agricultura do Futuro". Londrina-PR. 2007.

56. PINHEIRO, H.T.; JOYEUX, J.C. Pescarias multi- específicas na região da foz do rio doce, ES, Brasil: Características, problemas e opções para um futuro sustentável. Braz. J.Aquatic Science and Technology. , v. 11, no 2, p. 15-23, 2007.

57. POSEY, D.A. Etnobiologia: teoria e prática. In: RIBEIRO, B. (Ed.). Suma etnológica brasileira- 1 Etnobiologia. pp. 15-251. Vozes/ Finep, Petrópolis. 1987.

58. PUPO, M.M.; SOTO, J.M.R; HANAZAKI, N. Captura incidental de tartarugas marinhas na pesca artesanal da Ilha de Santa Catarina, SC. Biotemas, v.19 (4), p. 63-72, 2006.

59. RODRIGUES, R.A. e MAIA, L.P. Caracterização sócio-econômica das comunidades de pescadores do município de Aquiraz-Ceará. Arquivos de Ciências do Mar, 40(1): 16-23. 2007.

60. SANTOS, A.C.L.; BITTENCOURT,C.F.; ARAÚJO FILHO, R.J.P.; OLIVEIRA, P.G.V. Caracterização da pesca e perfil socioeconômico do pescador que atua sobre as Pontes do Recife, PE. Boletim do Instituto da Pesca, São Paulo, 40(2): 291 - 298, 2014.

61. SANTOS, G.M; SANTOS, A.C.M. Sustentabilidade da pesca na Amazônia. Estudos Avançados. 
v.19 (54), p. 165-182. 2005.

62. SANTOS, K.P.P. Etnobotânica e Etnozoologia dos Pescadores Artesanais do Município de União, Teresina/ PI, Brasil. Teresina, 2013. Dissertação (Mestrado) Programa de Pós Graduação em Desenvolvimento e Meio ambiente, Universidade Federal do Piauí, Teresina, 135p. 2013.

63. SCHORK, G.; HERMES-SILVA, S.; BEUX, L.F.; ZANIBONI-FILHO, E.; NUÑER, A.P de O. Diagnóstico da pesca artesanal na usina hidroelétrica de Machadinho, alto Rio Uruguai - Brasil. Boletim do Instituto de Pesca, 38(2): 97-108. 2012.

64. SILVA, M. da C.; OLIVEIRA, A.S.; NUNES, G. de Q. Caracterização socioeconômica da pesca artesanal no município de conceição do Araguaia, estado do Pará. Amazônia. Ciência e Desenvolvimento. Belém, v. 2, n. 4. p. 37-51. 2007.

65. SILVANO, R.A.M. Ecologia de três comunidades de pescadores do rio Piracicaba (SP). Ampinas, 1997. Dissertação de Mestrado. Programa de Pós - Graduação em Ecologia. Universidade Estadual de Campinas, Campinas, 147p. 1997.

66. SOUSA, R. da. S. Etnobotânnica e Etnozoologia de Comunidades Pesqueiras da Área de Proteção Ambiental (APA) do Delta do Parnaíba, nordeste do Brasil. Teresina, 2010. Dissertação (Mestrado) Programa de Pós - Graduação em Desenvolvimento e Meio ambiente, Universidade Federal do Piauí, Teresina, 175p. 2010.

67. SOUSA, R.S.; HANAZAKI, N; LOPES, J.B.; BARROS, R.F.M. Are Gender and Age Important in Understanding the Distribution of Local Botanical Knowledge in Fishing Communities of the Parnaíba Delta Environmental Protection Area? Ethnobotany Research \& Applications, v. 10, p. 551-560, 2012.

68. SOUZA, M.R; BARRELA, W. Conhecimento popular sobre peixes numa comunidade caiçara da estação ecológica de Juréia-Itatins/SP. Boletim do Instituto de Pesca, São Paulo, v. 27(2), p.123 - 130, 2001.

69. YANES, L; PRIMERA, C. Condiciones de trabajo y salud de los pescadores artesanales Del occidente de Venezuela. Salud de los Trabajadores, vol.14 n.2, Maracay Dec. 2006.

70. ZANCHETT, S.S. Memória e História: A Formação da Colônia de Pescadores Profissionais Artesanais "Z-2 RONDON PACHECO" DE COXIM-MS. Revista do curso de História/UFMScampus de Coxim, p 63- 84. 2015. 